\title{
Numerical study of two dimensional laminar boundary layer compressible flow with pressure gradient and heat and mass transfer
}

\author{
N. Kafoussias *, A. Karabis, M. Xenos \\ Department of Mathematics, Section of Applied Analysis, University of Patras, GR-26500 Patras, Greece
}

Received 2 June 1998; received in revised form 5 October 1998; accepted 12 November 1998

(Communicated by E.S. ŞUHUBi)

\begin{abstract}
The aim of this work is the study of the two dimensional laminar compressible boundary layer flow, with an adverse pressure gradient in the presence of heat and mass transfer. The partial differential equations and their boundary conditions, describing the problem under consideration, are transformed using the compressible Falkner-Skan transformation and the numerical solution of the problem is obtained by using a modification of the well known Keller's-box method. The obtained numerical results for the velocity and temperature field, as well as for the associated boundary layer parameters, are shown in figures for different free-stream Mach numbers $M_{\infty}$ and for the case (i) of heating of the wall $\left(S_{\mathrm{w}}>1\right)$, (ii) of an adiabatic wall $\left(S_{\mathrm{w}}=1\right)$ and (iii) of cooling of the wall $\left(S_{\mathrm{w}}<1\right)$, followed by an extensive discussion. The analysis of these results showed that the flow field is noticeably influenced by the pressure gradient parameter, the velocity of suction or injection imposed at the wall, the heattransfer parameter $S_{\mathrm{w}}$ and the free-stream Mach number. It is hoped that this study will bring out some more insight into the problem of the boundary-layer control and form the basis for a more wide and detailed investigation of this interesting problem of Aerodynamics. (C) 1999 Elsevier Science Ltd. All rights reserved.
\end{abstract}

\section{Introduction}

Compressible flow occurs in many devices encountered in mechanical and aerospace engineering practice and a knowledge of the effects of compressibility on a flow is absolutely

\footnotetext{
${ }^{*}$ Corresponding author. Tel.: 00-30-61-997-396; fax: 00-30-61-997-163.

E-mail address: Nikaf@math.upatras.gr (N. Kafoussias)
} 
necessary for many industrial and engineering applications. Although the most obvious applications of compressible fluid flow theory are in the design of high speed aircraft, a knowledge of compressible fluid flow is also required in the design and operation of many devices commonly encountered in engineering practice. Among these applications are: gas turbines, stream turbines, reciprocating engines, natural gas transmission lines and combustion chambers [1]. The problem of compressible laminar boundary layer flow past a sharp flat plate, at high Reynolds number, has been extensively studied and, comprehensive reviews of the numerous works concerned with compressible boundary layers were given by Kuerti [2] and Young [3]. Details of special mathematical methods employed by various authors have been discussed by Curle [4] and Stewartson [5]. Although the flat plate and stagnation point are certainly the most important compressible-flow solutions, there are practical problems of variable velocity $u_{\mathrm{e}}(x)$ and temperature $T_{\mathrm{e}}(x)$ or $T_{\mathrm{w}}(x)$ where a method is needed of computing, at least approximately, the wall skin-friction and heat-flux distributions. The English translation of the monograph of Walz [6] is essentially devoted to the development of such approximate computations, mainly for laminar and also for turbulent boundary layers. Since the laminar boundary layer equations are well defined and essentially free of empiricism, they are, in principle, solvable to any accuracy by finite-difference methods, finite-volume methods or other numerical methods. Many workers suggested numerical approaches, and some of those are discussed in the texts by Cebeci and Smith [7], Schreier [8] and Anderson [9]. In most practical boundary-layer calculations, involving pressure gradients and heat transfer, it is necessary to predict the boundary layer over its whole length. However, in situations that give rise to strong adverse pressure gradients, as for instance in Howarth's linearly retarded flow [10], the boundary layer increases its thickness considerably in the downstream direction and the flow in it becomes reversed. This causes the decelerated fluid particles to be forced outwards, which means that the boundary layer is separated from the wall. Separation is mostly an undesirable phenomenon because it entails large energy losses. It is well recognized that the very effective method for the prevention of separation is boundary-layer suction. The application of suction, which was first tried by Prandtl, was later widely used in the design of aircraft wings and in more recent times is also applied to remove separation and to reduce drag [7,11,12]. The problem of compressible viscous flow is a broad one and a great deal of research has been published on this subject. However, there has been much less work in the literature on documentation of adverse pressure gradient effects, on the separation of the boundary layer, in the presence of heat and mass transfer [13]. This is one of the most important problems in boundary layer-theory because in many design problems as, for example, in the design of fan blades or airfoils, it is necessary to prevent flow separation in order to reduce the drag and to produce high lift $[7,14]$.

So, in this work an attempt is undertaken of studying the effects of the adverse pressure gradient on the separation of the compressible, steady, two-dimensional, laminar boundary layer flow, under the presence of a constant velocity of suction or injection imposed at the wall. The mathematical formulation of the problem is presented in Section 2, while in Section 3, the numerical solution of the system of equations, describing the problem under consideration, is obtained. In Section 4, numerical calculations are carried out for the purpose of the discussion of the results shown on graphs and followed by an extensive analysis. 


\section{Mathematical formulation of the problem}

The two most relevant applications of laminar, compressible boundary layer theory are the flatplate flow and stagnation-point flow. Both cases give insight into the general effect of compressibility on boundary-layer flows and are very useful for estimating the friction and heat transfer on slender bodies or blunt bodies, respectively. The equations governing the steady, compressible, two-dimensional boundary layer flow, of a heat conducting perfect gas, are the continuity, momentum and energy equations, which, in the absence of body forces, can be written as [15]

$$
\begin{aligned}
& \frac{\partial}{\partial x}(\rho u)+\frac{\partial}{\partial y}(\rho v)=0 \\
& \rho u \frac{\partial u}{\partial x}+\rho v \frac{\partial u}{\partial y}=-\frac{\mathrm{d} p}{\mathrm{~d} x}+\frac{\partial}{\partial y}\left(\mu \frac{\partial u}{\partial y}\right), \\
& \rho u \frac{\partial H}{\partial x}+\rho v \frac{\partial H}{\partial y}=\frac{\partial}{\partial y}\left[\frac{\mu}{\operatorname{Pr}} \frac{\partial H}{\partial y}+\mu\left(1-\frac{1}{\operatorname{Pr}}\right) u \frac{\partial u}{\partial y}\right]
\end{aligned}
$$

respectively, where $H$ is the total enthalpy of the fluid defined for a perfect gas by the expression $H=c_{\mathrm{p}} T+(1 / 2) u^{2}$, Pr the Prandtl number defined as $\operatorname{Pr}=\mu c_{\mathrm{p}} / k$ and the other quantities have their usual meaning.

With the use of Bernoulli's equation

$$
-\frac{\mathrm{d} p}{\mathrm{~d} x}=\rho_{\mathrm{e}} u_{\mathrm{e}} \frac{\mathrm{d} u_{\mathrm{e}}}{\mathrm{d} x}
$$

where the subscript e refers to the conditions at the edge of the boundary layer, Eq. (2) can be written now as

$$
\rho u \frac{\partial u}{\partial x}+\rho v \frac{\partial u}{\partial y}=\rho_{\mathrm{e}} u_{\mathrm{e}} \frac{\mathrm{d} u_{\mathrm{e}}}{\mathrm{d} x}+\frac{\partial}{\partial y}\left(\mu \frac{\partial u}{\partial y}\right) .
$$

The boundary conditions of the problem, including a transpiration velocity $v_{\mathrm{w}}$ at the wall, are

$$
\begin{aligned}
& y=0: u=0, v=v_{\mathrm{w}}(x), H=H_{\mathrm{w}}(x), \\
& y \rightarrow \delta: u=u_{\mathrm{e}}(x), H=H_{\mathrm{e}},
\end{aligned}
$$

where $\delta$ is the boundary layer thickness.

On introducing the compressible Falkner-Skan transformation, defined by

$$
\eta=\int_{0}^{y}\left(\frac{u_{\mathrm{e}}(x)}{v_{\mathrm{e}}(x) x}\right)^{1 / 2} \frac{\rho(x, y)}{\rho_{\mathrm{e}}(x)} \mathrm{d} y, \quad \psi(x, y)=\left(\rho_{\mathrm{e}} \mu_{\mathrm{e}} u_{\mathrm{e}} x\right)^{1 / 2} f(x, \eta)
$$

and the definition of the stream function $\psi$, for a compressible flow, that satisfies the continuity equation (1), by the relations 


$$
\rho u=\frac{\partial \psi}{\partial y}, \quad \rho v=-\frac{\partial \psi}{\partial x}
$$

the system of Eqs. (5), (3) and (6) become

$$
\begin{aligned}
& \left(b f^{\prime \prime}\right)^{\prime}+m_{1} f f^{\prime \prime}+m_{2}\left[c-\left(f^{\prime}\right)^{2}\right]=x\left(f^{\prime} \frac{\partial f^{\prime}}{\partial x}-f^{\prime \prime} \frac{\partial f}{\partial x}\right), \\
& \left(e S^{\prime}+d f^{\prime} f^{\prime \prime}\right)^{\prime}+m_{1} f S^{\prime}=x\left(f^{\prime} \frac{\partial S}{\partial x}-S^{\prime} \frac{\partial f}{\partial x}\right), \\
& \eta=0: f^{\prime}=0, \quad f_{\mathrm{w}}=f(0, x)=-\frac{1}{\left(u_{\mathrm{e}} \mu_{\mathrm{e}} \rho_{\mathrm{e}} x\right)^{1 / 2}} \int_{0}^{x} \rho_{\mathrm{w}} v_{\mathrm{w}}(x) \mathrm{d} x, \quad S=S_{\mathrm{w}}(x), \\
& \eta=\eta_{\mathrm{e}}: f^{\prime}=1, \quad S=1,
\end{aligned}
$$

where primes denote partial differentiation with respect to $\eta\left(()^{\prime}=\partial() / \partial \eta\right)$ and the quantities $b, m_{1}, m_{2}$, etc. are defined as follows

$$
\begin{aligned}
& b=C, \quad C=\frac{\rho \mu}{\rho_{\mathrm{e}} \mu_{\mathrm{e}}}, \quad c=\frac{\rho_{\mathrm{e}}}{\rho}, \quad d=\frac{C u_{\mathrm{e}}^{2}}{H_{\mathrm{e}}}\left(1-\frac{1}{\operatorname{Pr}}\right), \\
& e=\frac{b}{\operatorname{Pr}}, \quad S=\frac{H}{H_{\mathrm{e}}}, \\
& m_{1}=\frac{1}{2}\left[1+m_{2}+\frac{x}{\rho_{\mathrm{e}} \mu_{\mathrm{e}}} \frac{\mathrm{d}}{\mathrm{d} x}\left(\rho_{\mathrm{e}} \mu_{\mathrm{e}}\right)\right], \quad m_{2}=\frac{x}{u_{\mathrm{e}}} \frac{\mathrm{d} u_{\mathrm{e}}}{\mathrm{d} x}, \quad R_{x}=\frac{u_{\mathrm{e}} x}{v_{\mathrm{e}}} .
\end{aligned}
$$

So, the problem under consideration is described by the system of Eqs. (9) and (10), with boundary condition (11), whereas the various coefficients entering into these equations are defined by the expressions (12).

\section{Numerical solution of the problem}

To show the effect of heat and mass transfer on the compressible laminar boundary layer flow, over a porous plate, in the presence of an adverse pressure gradient we consider, as an example, the linearly retarded flow, known as Howarth's flow, in which the external velocity varies linearly with $x$, that is

$$
u_{\mathrm{e}}(\bar{x})=u_{\infty}(1-\bar{x}),
$$


where $u_{\infty}$ is the free-stream velocity, $\bar{x}=x / L$ and $L$ the length of the boundary surface. This flow model can be interpreted, for instance, as representing the potential flow along a flat wall which starts at $\bar{x}=0$ and which abuts on to another infinite wall at right angles to it at $\bar{x}=1(x=L)$. For the numerical calculations the length $L$ was taken equal to $8 \mathrm{~m}$ so that $x$ varies between $x=0$ and $x=8 \mathrm{~m}$. The numerical scheme used to solve the system of Eqs. (9)-(12) is a modified version of the Keller's-box method [16], described in detail in Refs. [7,15]. In this modified version, the governing equations are reduced to a first order system and are approximated using second order accurate central differences. However, it was found that the usual central difference approximation in the $x$ direction sometimes give rise to large but bounded oscillations in the numerical solutions. The oscillations reduce in magnitude as the $x$ step is reduced, but their entire elimination requires an extremely small streamwise steplength. Therefore, it was decided to use a backward difference modification to the Keller's-box method and the solutions obtained, though now formally only first-order accurate in $x$, showed no sign of oscillations even for large step lengths. The resulting non-linear algebraic system is solved using a multi-dimensional NewtonRaphson iteration scheme where the Jacobian (or iteration) matrix is computed numerically rather than being prescribed by the programmer. This technique has been used successfully in other recent papers where the explicit specification of the Jacobian is extremely lengthy $[17,18]$.

Numerical calculation were carried out for air, at about $T_{\infty}=300 \mathrm{~K}(\operatorname{Pr}=0.708)$, for $S_{\mathrm{w}}=$ $H_{\mathrm{w}} / H_{\mathrm{e}}=2, S_{\mathrm{w}}=1$ and $S_{\mathrm{w}}=0.5$, thus covering the cases in which the wall is heated, adiabatic and cooled, respectively. It is worth mentioning here that the requirement that the dimensionless heat-transfer parameter $S_{\mathrm{w}} \neq 1$ corresponds to a flow with heat transfer, whereas the requirement $S_{\mathrm{w}}=1$ corresponds to a flow with no heat transfer between the wall and the fluid (adiabatic flow). On the other hand, the value $S_{\mathrm{w}}=2\left(S_{\mathrm{w}}>1\right)$ corresponds to the case of heating of the wall whereas the value $S_{\mathrm{w}}=0.5\left(S_{\mathrm{w}}<1\right)$ to the case of cooling of the wall.

It is known that the best way of removing a small portion of the boundary layer flow is to develop a continuous porous surface. This solution is not always easy to apply for both structural and aerodynamics difficulties. At the present time, the best methods to approach a continuous suction are to use of spanwise slots or strips of perforated material. Suction has been very often used as an aerodynamic flow control technique to prevent laminar to turbulent boundary layer transition as well as turbulent flow separation. Application of suction along the leading edge of a wing stabilize the boundary layer and prevent transition from laminar to turbulent flow over the wing [12]. Small amounts of suction are very efficient for transition control. However, if the suction velocity $v_{\mathrm{w}}$ is too large the boundary layer could be very thin and the roughness effects be enhanced. As a result, negative effects in terms of drag reduction could be recovered [14]. So, the suction/injection velocity at the wall, $v_{\mathrm{w}}$, was taken constant and equal to $v_{\mathrm{w}}= \pm 10 \times 10^{-5} u_{\infty}$ for the case of heating of the wall $\left(S_{\mathrm{w}}=2\right), v_{\mathrm{w}}= \pm 5 \times 10^{-5} u_{\infty}$ for an adiabatic wall $\left(S_{\mathrm{w}}=1\right)$ and $v_{\mathrm{w}}= \pm 1 \times 10^{-5} u_{\infty}$ for the case of cooling of the wall $\left(S_{\mathrm{w}}=0.5\right)$, which is a valid assumption in order to ensure that the flow with suction or injection at the wall satisfies the simplifying conditions which form the basis of the boundary layer theory [11]. Also, $v_{\mathrm{w}}$ represents the velocity of suction or injection at the wall according as $v_{\mathrm{w}}<0$ or $v_{\mathrm{w}}>0$, respectively. The case $v_{\mathrm{w}}=0$ corresponds to an impermeable wall (no suction). The free-stream values $\mu_{\infty}, u_{\infty}, \rho_{\infty}$ and $H_{\infty}$ were calculated from the formulas

$$
\mu_{\infty}=1.45 \times 10^{-6} T_{\infty}^{3 / 2} /\left(T_{\infty}+110.33\right) \text { (Sutherland's law) }
$$




$$
\begin{aligned}
& u_{\infty}=20.04 M_{\infty} \sqrt{T_{\infty}}, \\
& \rho_{\infty}=P_{\infty} / 287 T_{\infty}, \\
& H_{\infty}=1005.7 T_{\infty}+\frac{1}{2} u_{\infty}^{2}\left(c_{\mathrm{p}}=1005.7\right),
\end{aligned}
$$

for different values of the free-stream Mach number $M_{\infty}$, whereas the edge values $T_{\mathrm{e}}$ and $P_{\mathrm{e}}$ were calculated by using the formulas

$$
T_{\mathrm{e}}=T_{\infty}\left\{1-\frac{\gamma-1}{2} M_{\infty}^{2}\left[\left(\frac{u_{\mathrm{e}}}{u_{\infty}}\right)^{2}-1\right]\right\}, \quad P_{\mathrm{e}}=P_{\infty}\left(\frac{T_{\mathrm{e}}}{T_{\infty}}\right)^{\gamma /(\gamma-1)},
$$

where $\gamma=c_{\mathrm{p}} / c_{\mathrm{v}}=1.4$.

The edge values $\mu_{\mathrm{e}}, \rho_{\mathrm{e}}$ and $H_{\mathrm{e}}$ were calculated by using formulas identical to those given by Eqs. (14), (16) and (17), respectively, except that free stream values $(\infty)$ of temperature, pressure and velocity were replaced by their edge values (e). It is worth mentioning here that Sutherland's law, Eq. (14), is an adequate approximation for the variation of viscosity $\mu$ with temperature $T$, for air. For viscous fluids, Ling and Dybbs [19] suggested a viscosity dependence on temperature $T$ of the form

$$
\mu=\mu_{\infty} /\left[1+\gamma^{*}\left(T-T_{\infty}\right)\right],
$$

so that viscosity is an inverse linear function of temperature $T$. Eq. (19) can also be written as

$$
\frac{1}{\mu}=\alpha\left(T-T_{\mathrm{r}}\right)
$$

where

$$
\alpha=\gamma^{*} / \mu_{\infty} \text { and } T_{\mathrm{r}}=T_{\infty}-1 / \gamma^{*} .
$$

In the above relation (20), both $\alpha$ and $T_{\mathrm{r}}$ are constants and their values depend on the reference state and $\gamma^{*}$, a thermal property of the fluid. For air, for instance,

$$
\frac{1}{\mu}=-123.2(T-742.6) \quad \text { based on } T_{\infty}=293 \mathrm{~K}\left(20^{\circ} \mathrm{C}\right) .
$$

The data used for this correlation were taken from Ref. [20]. Although Ling's and Dybb's model is more accurate, its validity is limited to small temperature differences. For instance, Eq. (22) is good to within $1.2 \%$ from 278 to $373 \mathrm{~K}$. So, in our study we adopted Sutherland's law for viscosity variation since in high-speed shear layers temperature differences are not small compared with the absolute temperature. 


\section{Results and discussion}

A detailed analysis of the problem under consideration must include the study of the velocity field, the temperature field, the wall shear parameter, the wall heat transfer parameter and the influence of the dimensionless parameters, entering into the problem, on them. It is also interesting to examine the behavior of the boundary-layer parameters like the momentum thickness $\theta$, the displacement thickness $\delta^{*}$, the shape factor $H=\delta^{*} / \theta$, etc. However, the most important quantities, for engineering purposes, are the skin friction coefficient and the heat transfer coefficient which can be defined by the following relations.

$$
c_{\mathrm{f}}=\frac{\tau_{\mathrm{w}}}{(1 / 2) \rho_{\mathrm{e}} u_{\mathrm{e}}^{2}} \quad \text { and } \quad \mathrm{Nu}_{x}=\frac{\dot{q}_{\mathrm{w}} x}{k\left(T_{\mathrm{w}}-T_{\mathrm{e}}\right)}
$$

where

$$
\tau_{\mathrm{w}}=\left[\mu \frac{\partial u}{\partial y}\right]_{y=0} \quad \text { and } \quad \dot{q}_{\mathrm{w}}=-\left[k \frac{\partial T}{\partial y}\right]_{y=0} .
$$

Using Eqs. (7), (8) and (12) the above quantities can be written in the form

$$
c_{\mathrm{f}}=\frac{2 C_{\mathrm{w}}}{\sqrt{R_{x}}} f_{\mathrm{w}}^{\prime \prime} \quad \text { and } \quad \mathrm{Nu}_{x}=-\frac{C_{\mathrm{w}} \sqrt{R_{x}}}{1-S_{\mathrm{w}}} S_{\mathrm{w}}^{\prime}\left(S_{\mathrm{w}} \neq 1\right),
$$

where $f_{\mathrm{w}}^{\prime \prime}=f^{\prime \prime}(x, 0)$ is the dimensionless wall shear parameter and $S_{\mathrm{w}}^{\prime}\left(\right.$ or $\left.-S_{\mathrm{w}}^{\prime}\right)=S^{\prime}(x, 0)$ is the dimensionless wall heat transfer parameter. So, due to lack of space, we restrict ourselves to some representative results showing the effect of the suction/injection velocity $v_{\mathrm{w}}$ on the velocity field and temperature field, as well as the effect of free-stream Mach number $M_{\infty}$ and the heat transfer parameter $S_{\mathrm{w}}$, and we examine in detail the effect of $v_{\mathrm{w}}, M_{\infty}$ and $S_{\mathrm{w}}$ especially on the wall shear parameter $f_{\mathrm{w}}^{\prime \prime}$ and the wall heat transfer parameter $-S_{\mathrm{w}}^{\prime}$. So, the obtained numerical results for the case of suction/injection $\left(v_{\mathrm{w}} \neq 0\right)$ or with no suction $\left(v_{\mathrm{w}}=0\right)$, for $\operatorname{Pr}=0.708$ and for different values of the free stream Mach number $M_{\infty}=$ Minf are shown on figures for all possible cases of $S_{\mathrm{w}}$, that is (i) for the case of heating of the wall $\left(S_{\mathrm{w}}>1\right)$, (ii) for the case of an adiabatic wall $\left(S_{\mathrm{w}}=1\right)$, and (iii) for the case of cooling of the wall $\left(S_{\mathrm{w}}<1\right)$.

\subsection{Heating of the wall $\left(S_{\mathrm{w}}>1\right)$}

Figs. 1 and 2 show the variation of the dimensionless velocity profiles $f^{\prime}(\eta)$ and dimensionless temperature profiles $S(\eta)$ for the case of heating the wall $\left(S_{\mathrm{w}}>1\right)$, at a typical distance $x=0.3 \mathrm{~m}$ from the leading edge of the plate and for the case of suction $\left(v_{\mathrm{w}}<0\right)$, injection $\left(v_{\mathrm{w}}>0\right)$ or for the case of an impermeable wall $\left(v_{\mathrm{w}}=0\right.$, no suction). The velocity profiles are strongly affected by transpiration velocity $v_{\mathrm{w}}$. The suction profile has negative curvature and delay separation whereas injection profile is less stable and tends to display a point of inflection. On the other hand, the temperature profiles are also greatly influenced by the suction/injection and the temperature gradient at the wall, in the $\eta$ direction, is greater in the case of injection than that of suction. It is worth mentioning here that the velocity field as well as the temperature field is more influenced in the case of injection than that of suction. Quantitatively, when $\eta=2.4$ application of suction helps in 


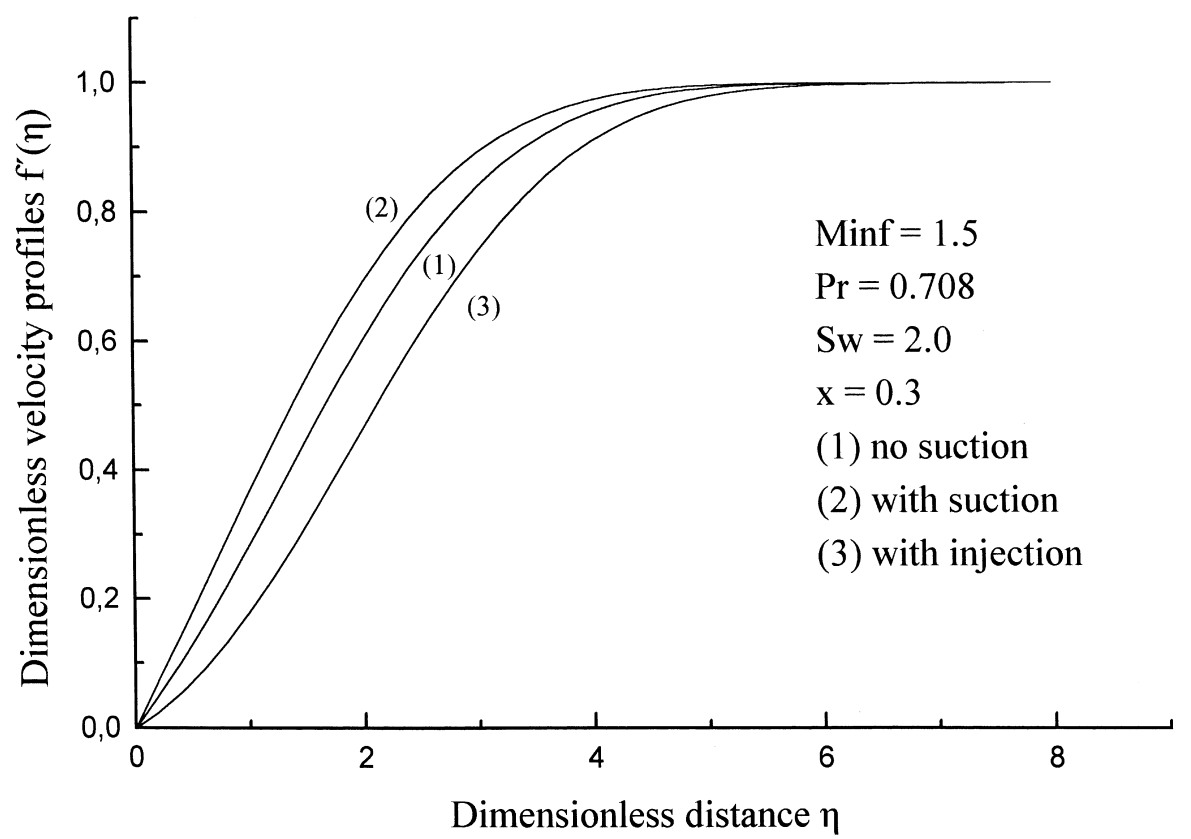

Fig. 1. Variation of the dimensionless velocity profiles $f^{\prime}(\eta)$ for $x=0.3$.

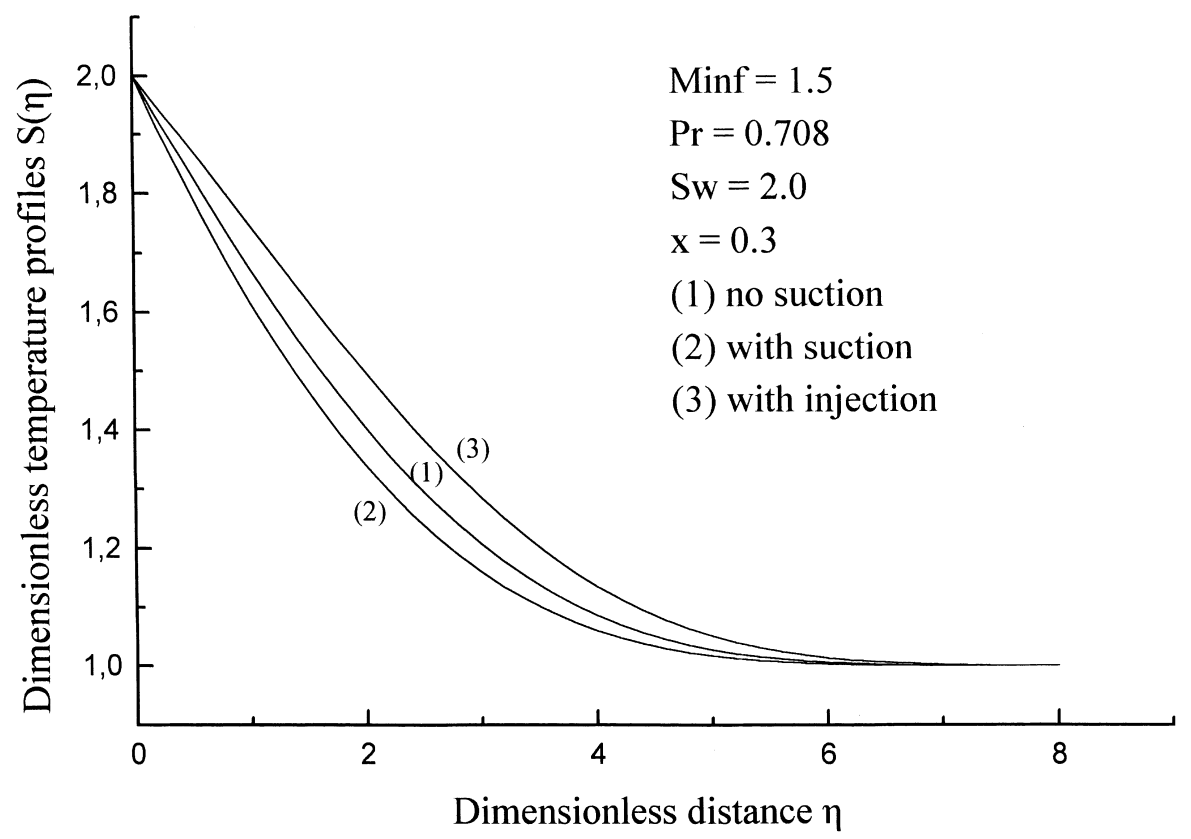

Fig. 2. Variation of the dimensionless temperature profiles $S(\eta)$ for $x=0.3$. 
increasing $f^{\prime}(\eta)$ by $10.75 \%$, whereas the corresponding decrease in the case of injection is $18 \%$. For the temperature field the corresponding "changes" are $4.43 \%$ and $6.9 \%$, respectively. Figs. 3 and 4 show the variation of the wall shear parameter $f_{\mathrm{w}}^{\prime \prime}$, with the distance $x$, when $M_{\infty}=0.375$ and 1.5 , respectively. It is observed that the Mach number has a considerable influence on the separation point which is moved towards the leading edge as $M_{\infty}$ increases. What is more interesting though, is the influence of suction/injection velocity $v_{\mathrm{w}}$ on the separation point. When $M_{\infty}=1.5$, for instance (Fig. 4), the separation point moves from $x \approx 0.515$ to $x \approx 0.770$, in the case of suction, whereas, in the case of injection, it moves from $x \approx 0.515$ to $x \approx 0.370$. This fact verifies the assertion that application of suction is the best way for the boundary layer control and prevent separation or transition from laminar to turbulent flow. On the other hand, Figs. 5 and 6 show the variation of the wall heat transfer parameter $-S_{\mathrm{w}}^{\prime}$ under the same circumstances. It is concluded that the wall heat transfer parameter is affected by compressibility as well as by the suction/injection velocity $v_{\mathrm{w}}$, imposed at the wall. It is also interesting to note that in this case though, the injection velocity has the same effect on the heat transfer parameter $-S_{\mathrm{w}}^{\prime}$ as the suction velocity. To quantify this statement we note that when $M_{\infty}=1.5$ and $x=0.3$, the value of the wall heat transfer parameter, in the case of an impermeable wall, is found to be equal to 0.3464 . In the case of suction there is $25.46 \%$ increase in the value of $-S_{\mathrm{w}}^{\prime}$, and in the case of injection the corresponding decrease is $25.23 \%$.

\subsection{Adiabatic wall $\left(S_{\mathrm{w}}=1\right)$}

In this case the wall temperature condition $S_{\mathrm{w}}=1$, actually the total enthalpy ratio on the wall $\left(H_{\mathrm{w}} / H_{\mathrm{e}}\right)=1$, corresponds to an adiabatic wall or to a flow in which the heat transfer

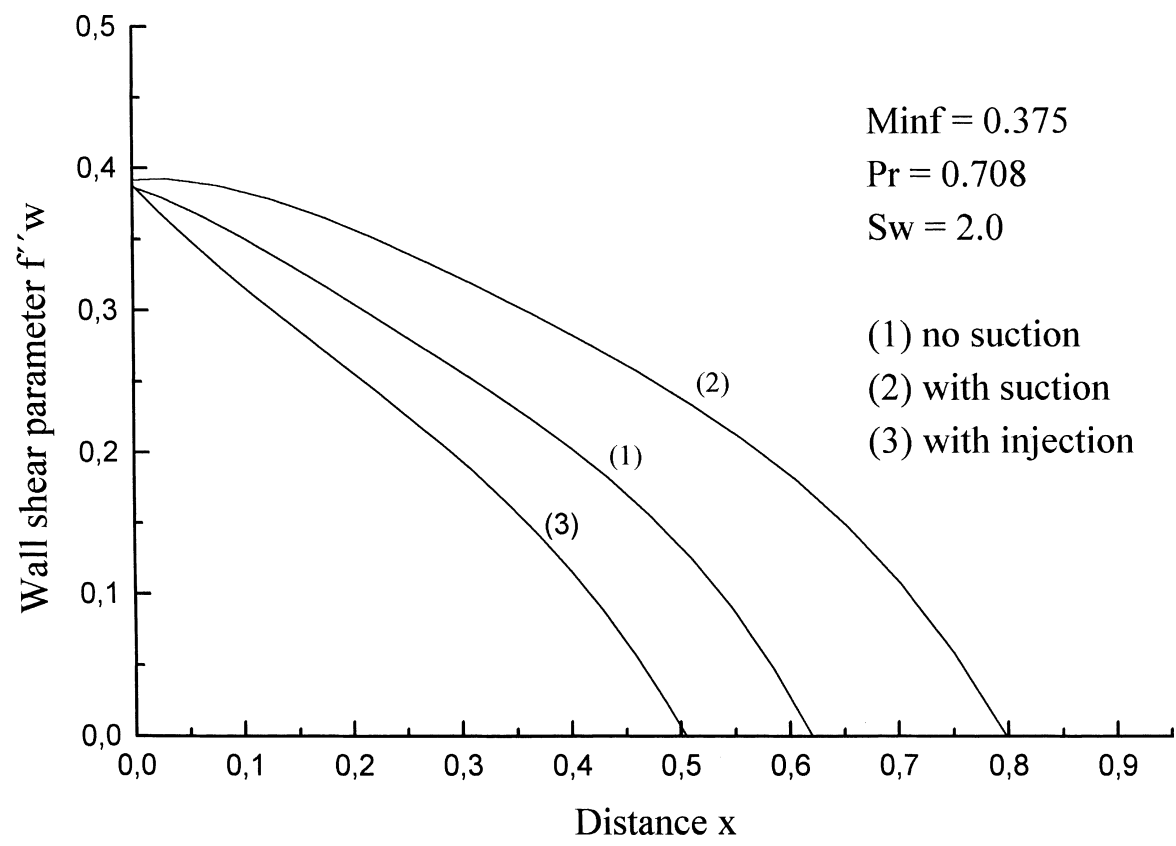

Fig. 3. Variation of the dimensionless wall shear parameter $f_{\mathrm{w}}^{\prime \prime}$ for $M_{\infty}=0.375$. 


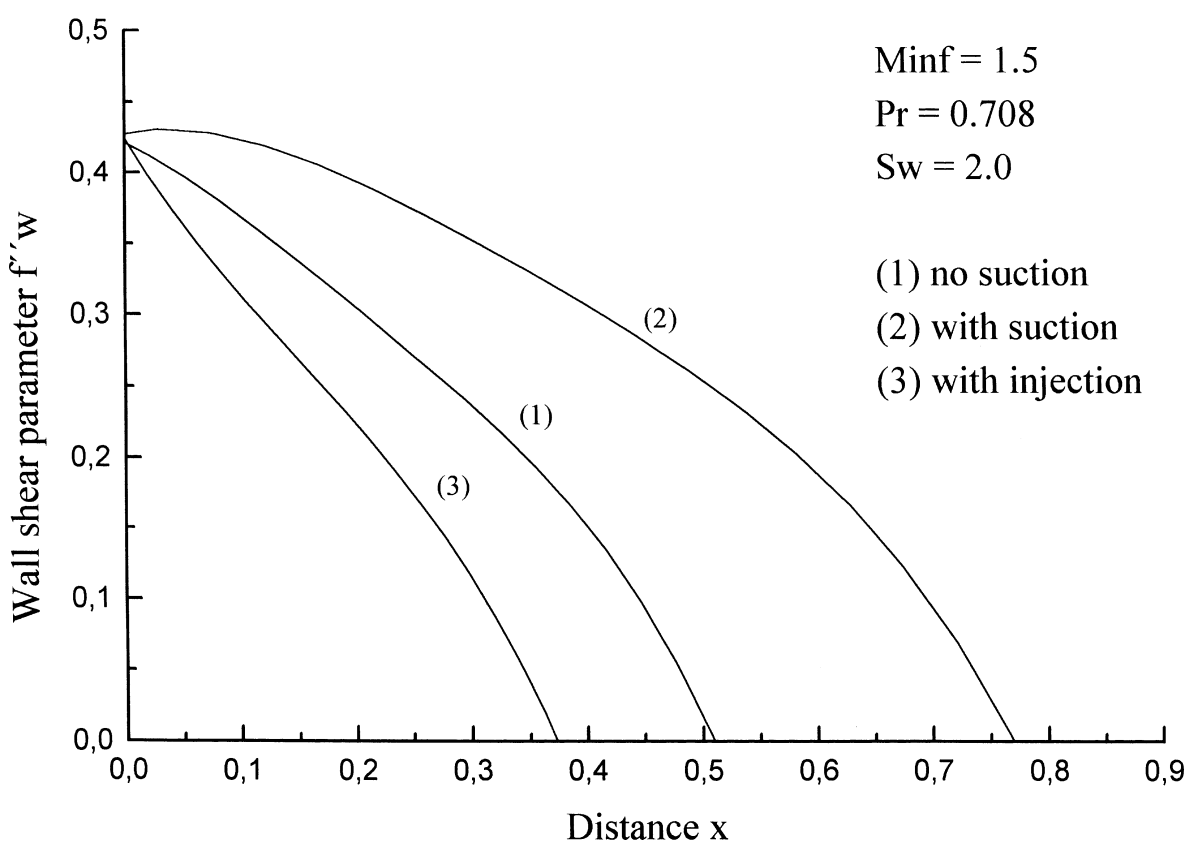

Fig. 4. Variation of the dimensionless wall shear parameter $f_{\mathrm{w}}^{\prime \prime}$ for $M_{\infty}=1.5$.

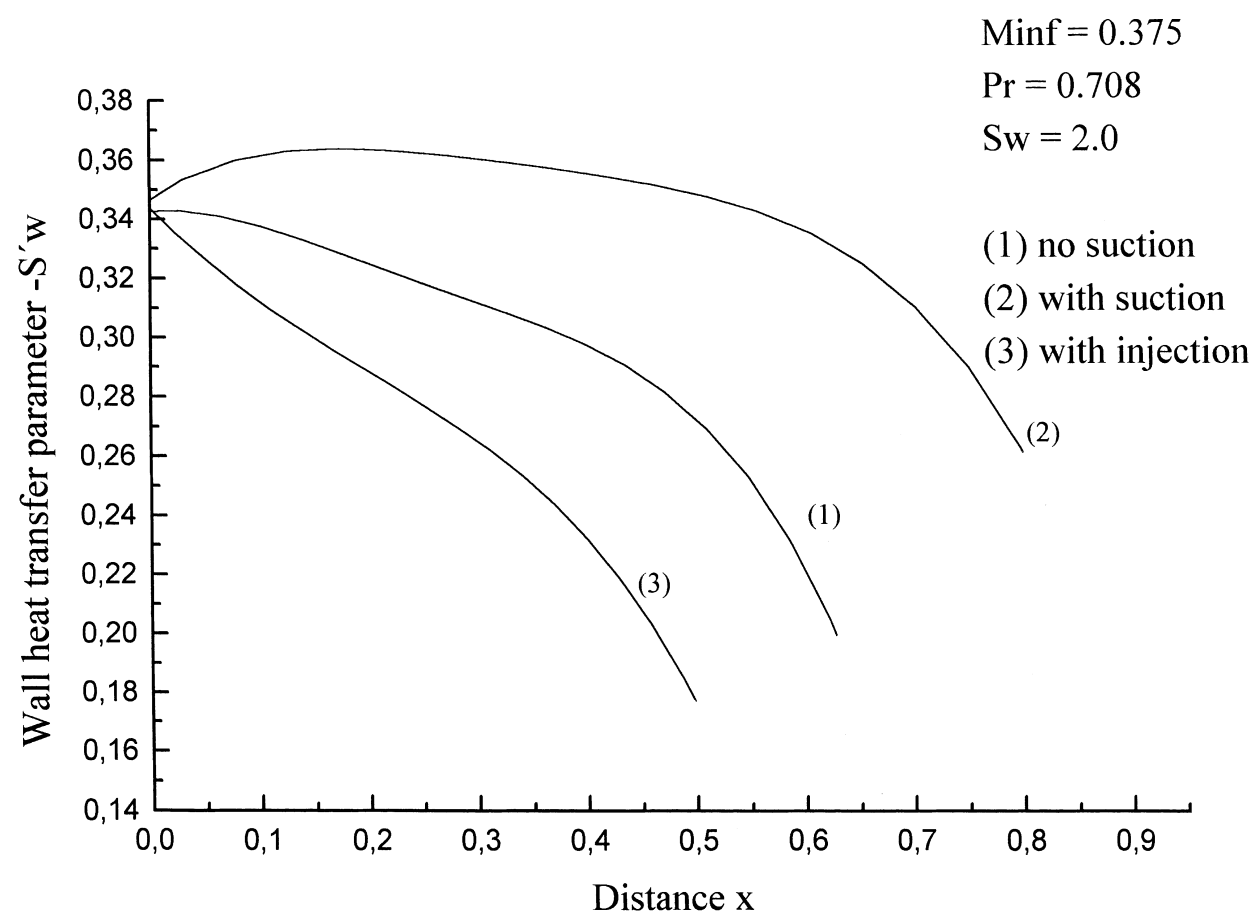

Fig. 5. Variation of the dimensionless wall heat transfer parameter $-S_{\mathrm{w}}^{\prime}$ for $M_{\infty}=0.375$. 


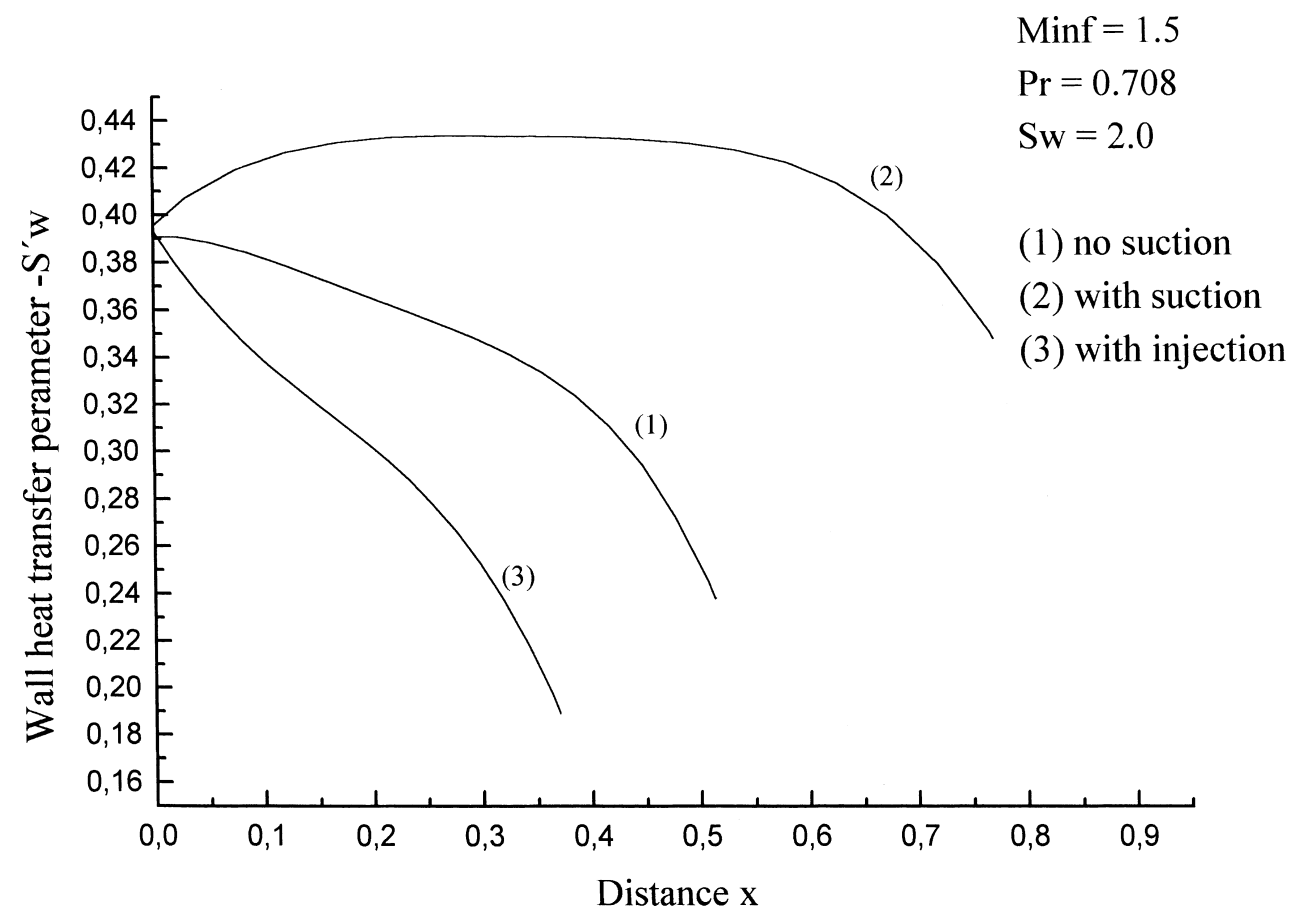

Fig. 6. Variation of the dimensionless wall heat transfer parameter $-S_{\mathrm{w}}^{\prime}$ for $M_{\infty}=1.5$.

through the surface to the fluid is zero. In such a case it is worth examining only the velocity field as well as the wall shear parameter $f_{\mathrm{w}}^{\prime \prime}$ for the various values of the parameters entering into the problem under consideration. So, Fig. 7 shows the variations of the dimensionless velocity profiles $f^{\prime}(\eta)$ under the same circumstances as those in Fig. 1. It is concluded that in this case also $\left(S_{\mathrm{w}}=1\right)$ the velocity profiles present the same behavior, qualitatively at least, as that in the case of heating of the wall (Fig. 1). The effects of free-stream Mach number $M_{\infty}$ on the wall shear parameter $f_{\mathrm{w}}^{\prime \prime}$, for the case of suction/injection or for an impermeable wall are shown in Figs. 8 and 9 . It is worth noting here $\left(S_{\mathrm{w}}=1\right)$ that in the case of suction, as the Mach number increases, the separation point moves downwards the surface and not towards the leading edge. Consequently, in the case of an adiabatic wall the application of suction is very effective in stabilizing the flow.

\subsection{Cooling of the wall $\left(S_{\mathrm{w}}<1\right)$}

Figs. 10 and 11 show the dimensionless velocity and temperature profiles, respectively, at a typical distance $x=0.3 \mathrm{~m}$ from the leading edge of the surface, for $M_{\infty}=1.5$ and $S_{\mathrm{w}}=0.5$. It is observed that, qualitatively, these profiles present the same behavior to those obtained for $S_{\mathrm{w}}=2$. The quantitative difference is due to the fact that in this case $\left(S_{\mathrm{w}}=0.5\right)$ the suction/injection velocity $v_{\mathrm{w}}$, imposed at the wall $\left(v_{\mathrm{w}}=\mp 10^{-5} u_{\infty}\right)$, is ten times less than the corresponding one in the case of heating of the wall $\left(v_{\mathrm{w}}=\mp 10^{-4} u_{\infty}\right)$. The results in Figs. 12 and 13, presenting the effect of $M_{\infty}$ and $v_{\mathrm{w}}$ on the wall shear parameter $f_{\mathrm{w}}^{\prime \prime}$, show that in this case too, the compressibility has 


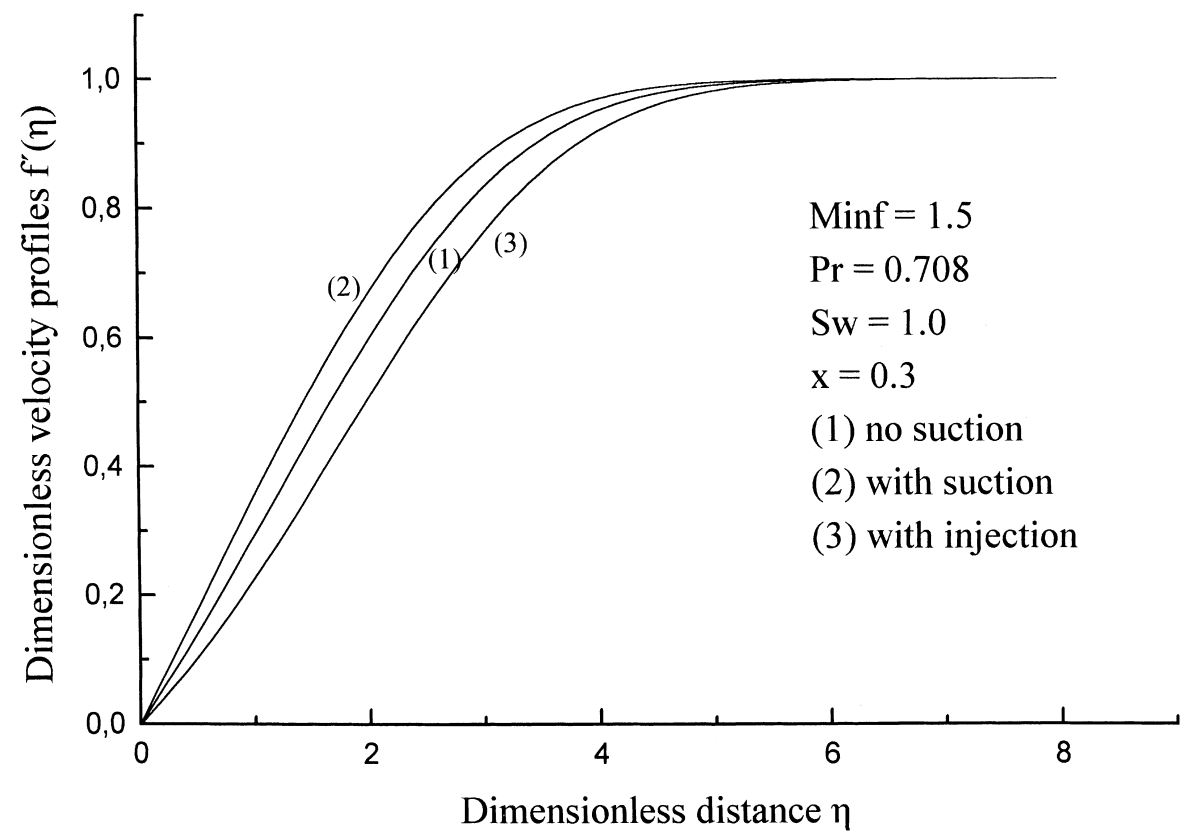

Fig. 7. Variation of the dimensionless velocity profile $f^{\prime}(\eta)$ for $x=0.3$.

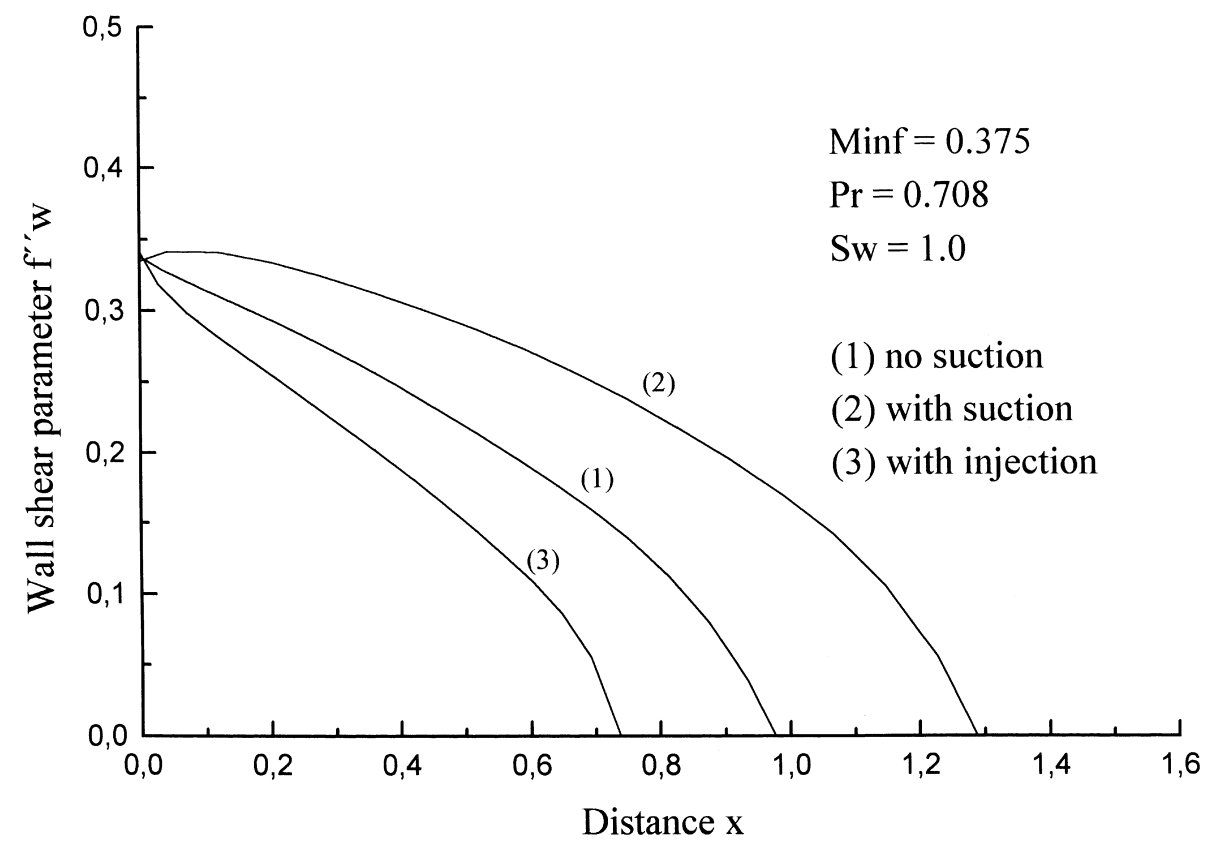

Fig. 8. Variation of the dimensionless wall shear parameter $f_{\mathrm{w}}^{\prime \prime}$ for $M_{\infty}=0.375$. 


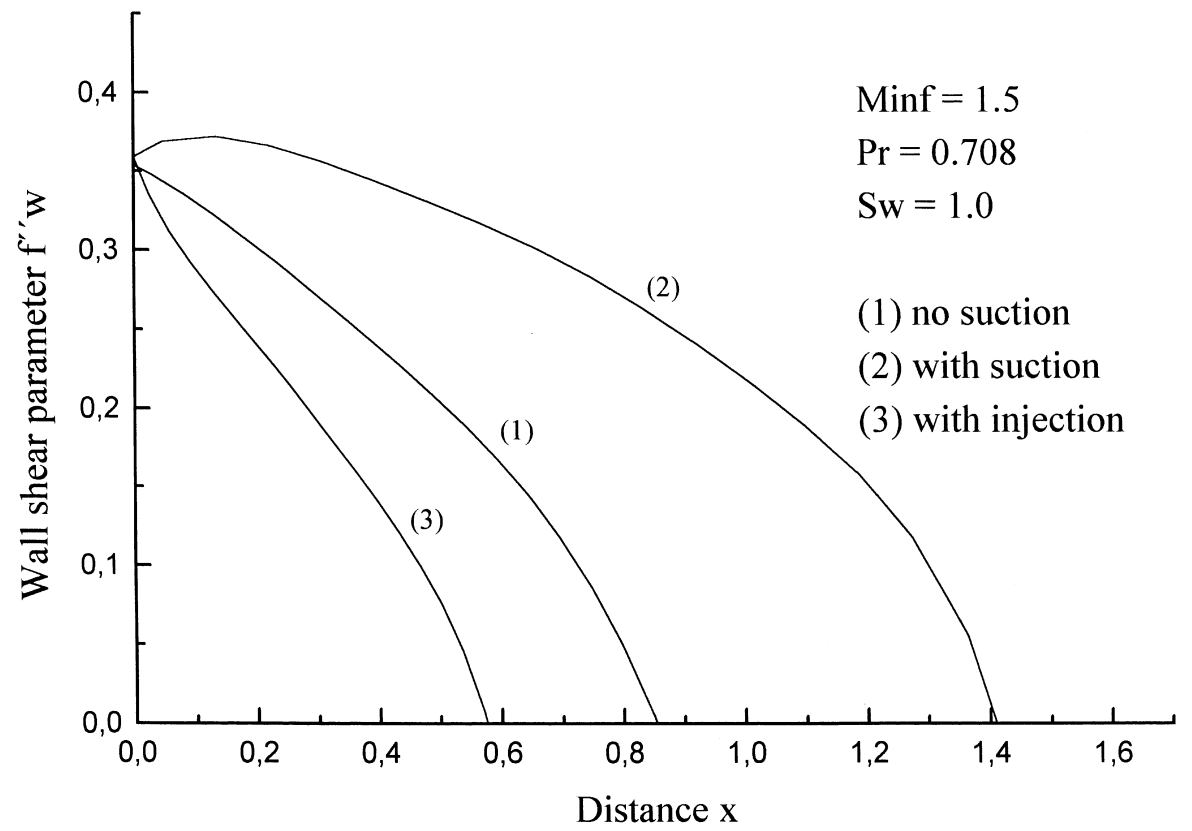

Fig. 9. Variation of the dimensionless wall shear parameter $f_{\mathrm{w}}^{\prime \prime}$ for $M_{\infty}=1.5$.

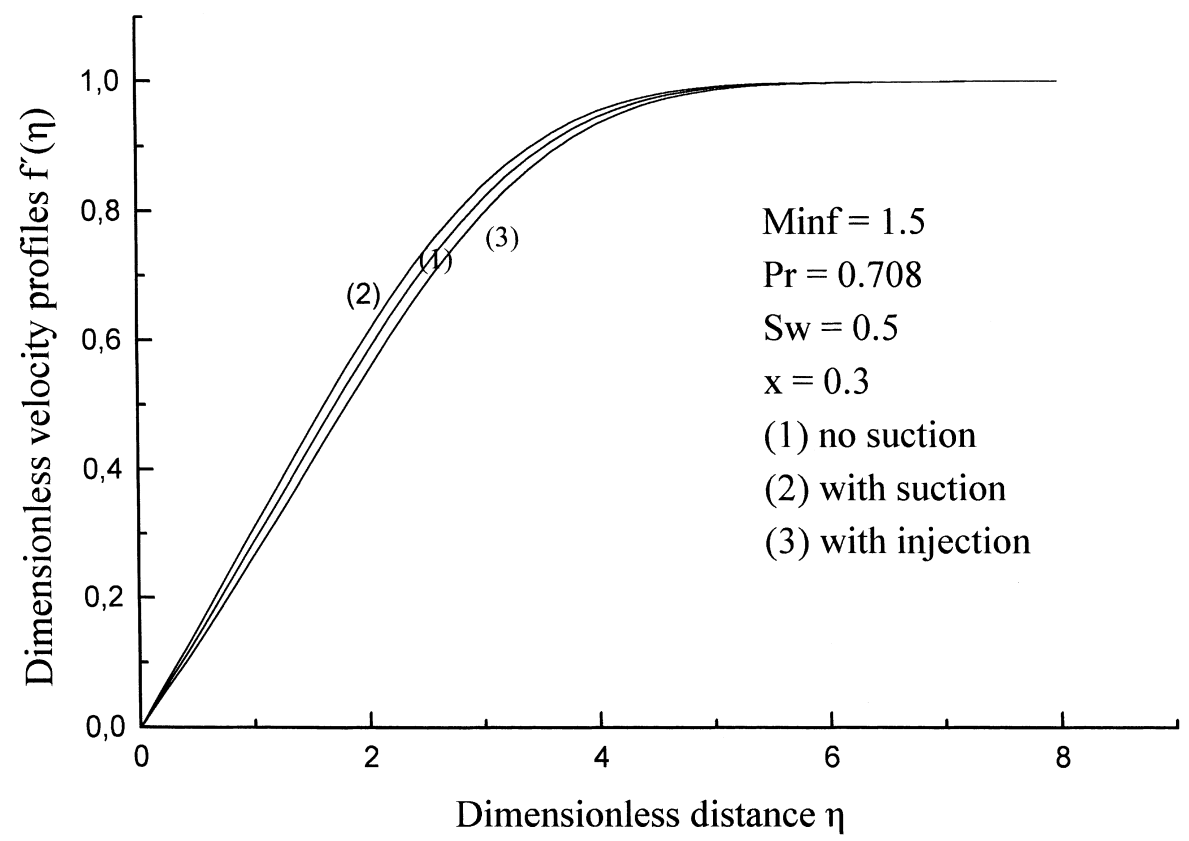

Fig. 10. Variation of the dimensionless velocity profile $f^{\prime}(\eta)$ for $x=0.3$. 


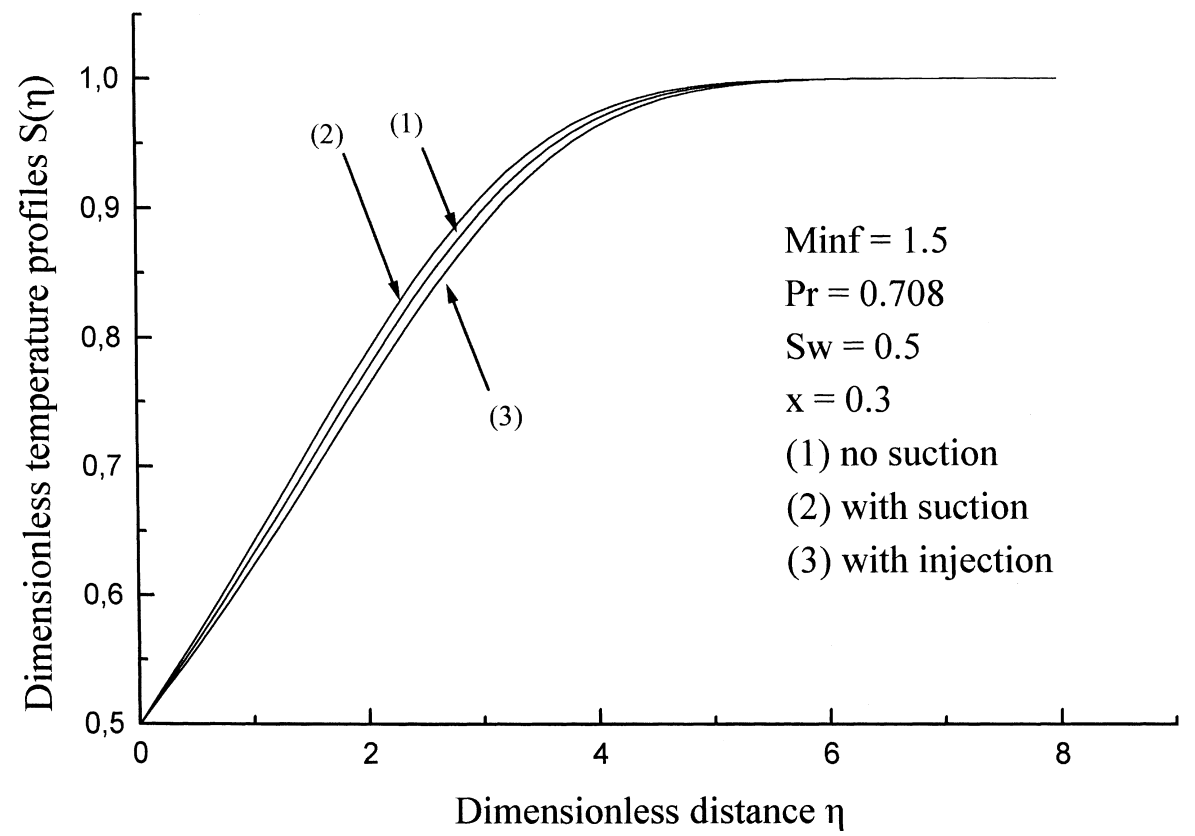

Fig. 11. Variation of the dimensionless temperature profiles $S(\eta)$ for $x=0.3$.

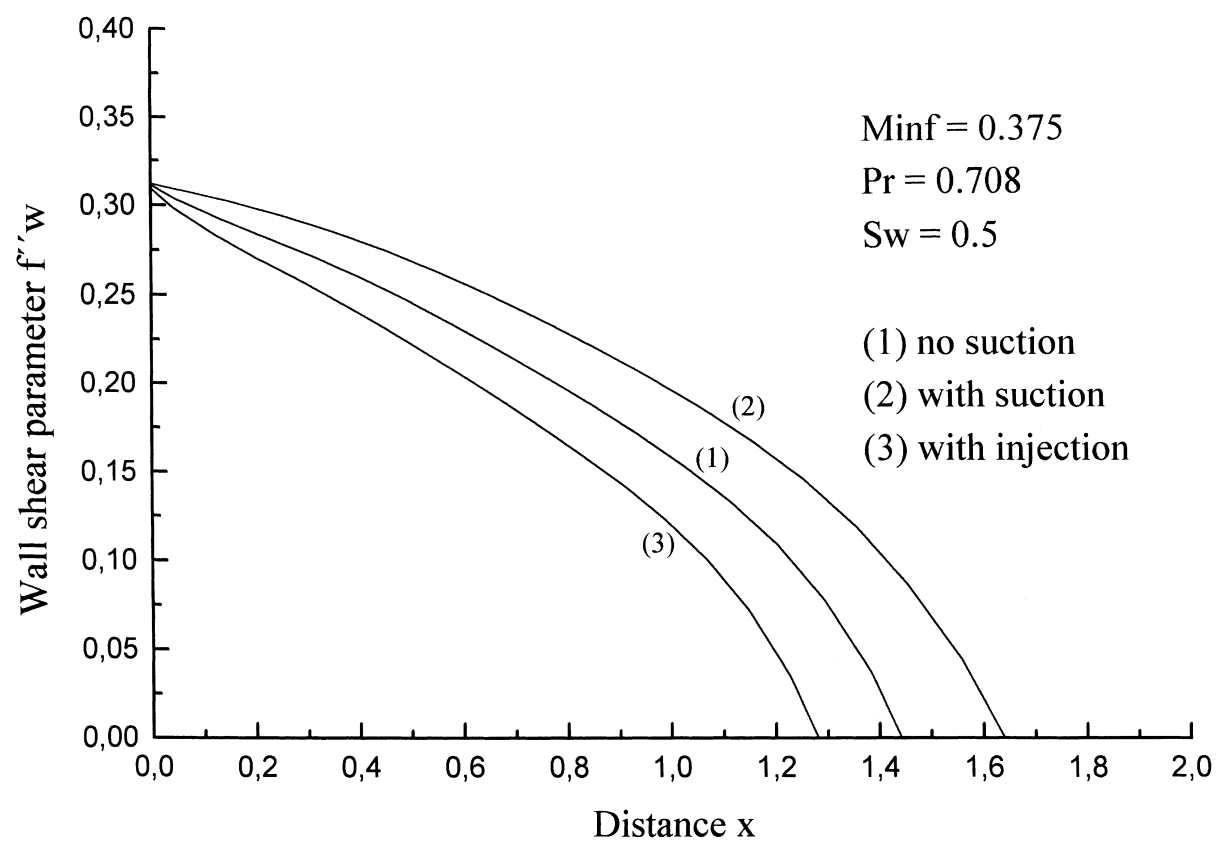

Fig. 12. Variation of the dimensionless wall shear parameter $f_{\mathrm{w}}^{\prime \prime}$ for $M_{\infty}=0.375$. 


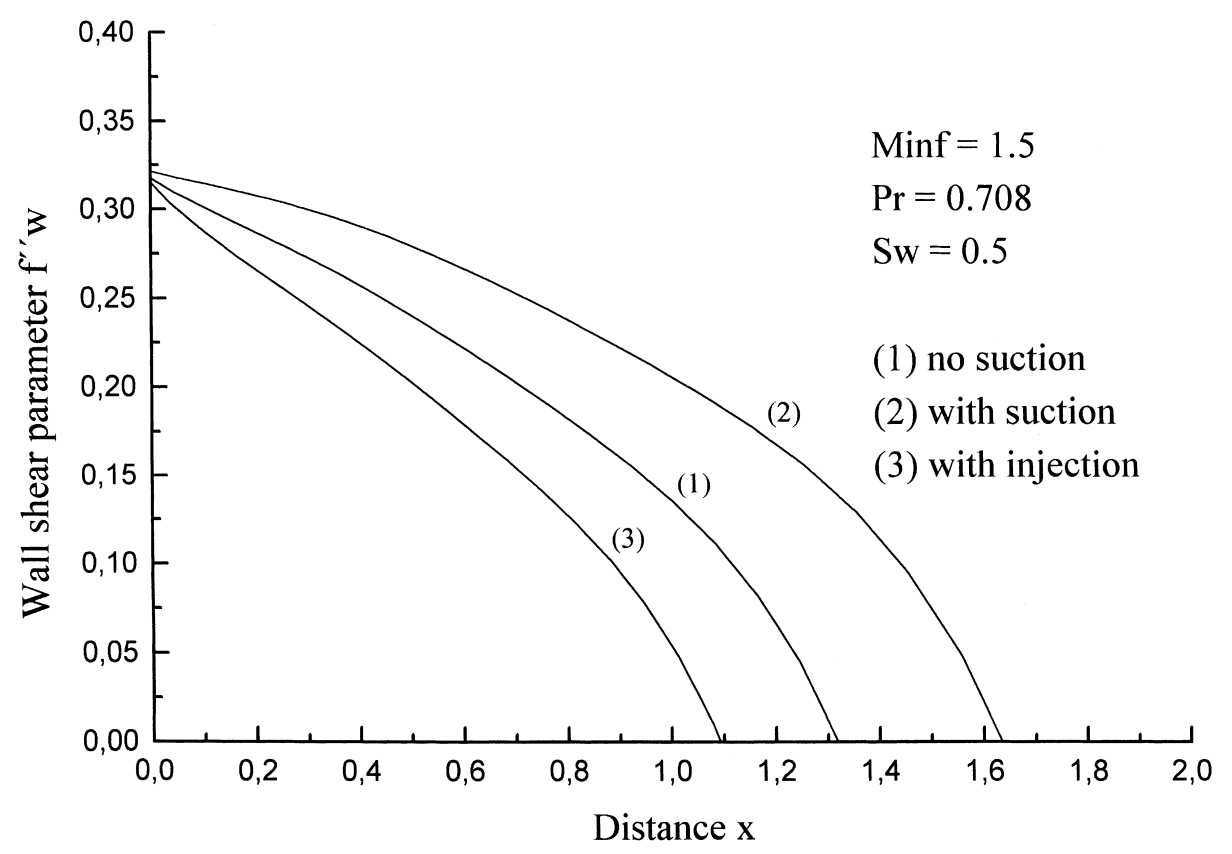

Fig. 13. Variation of the dimensionless wall shear parameter $f_{\mathrm{w}}^{\prime \prime}$ for $M_{\infty}=1.5$.

a considerable influence on the separation point. For an impermeable wall (no suction) the separation point moves from $x \approx 1.44$ for $M_{\infty}=0.375$ to $x \approx 1.32$ for $M_{\infty}=1.5$. In the case of injection, the separation point moves from $x=1.28$ for $M_{\infty}=0.375$ to $x \approx 1.09$ for $M_{\infty}=1.5$. However, in the case of suction, there is no appreciable difference of the location of the separation point for these values of Mach number $M_{\infty}$. Hence, it is concluded that in the case of cooling of the wall $\left(S_{\mathrm{w}}<1\right)$ and when the wall is subjected to a suction velocity, the location of separation is little affected by compressibility.

The variations of the wall heat transfer parameter $-S_{\mathrm{w}}^{\prime}$ are presented in Figs. 14 and 15 for $M_{\infty}=0.375$ and 1.5 , respectively. It is observed that, and in this case $\left(S_{\mathrm{w}}=0.5\right)$, the wall heat transfer parameter is appreciably influenced by compressibility as well as by the suction/injection velocity $v_{\mathrm{w}}$, imposed at the wall. It is also interesting to note that for higher values of freestream Mach number the wall heat transfer parameter $-S_{\mathrm{w}}^{\prime}$ is more influenced by the suction/ injection velocity $v_{\mathrm{w}}$ imposed at the wall. To quantify this statement we note that when $M_{\infty}=$ 0.375 and $x=0.6$, the value of $-S_{\mathrm{w}}^{\prime}$, in the case of an impermeable wall, is found to be equal to -0.12404 . In the case of suction there is $7.82 \%$ decrease in the value of $-S_{\mathrm{w}}^{\prime}$, and in the case of injection the corresponding increase is $7.74 \%$. However, when $M_{\infty}=1.5$ the corresponding changes are $13.01 \%$ and $12.31 \%$, respectively. Finally, Figs. 16 and 17 show the variations of the dimensionless wall shear parameter $f_{\mathrm{w}}^{\prime \prime}$, for $M_{\infty}=0.375$ and 1.5 , respectively, and for all cases of $S_{\mathrm{w}}$, when the wall is impermeable or is subjected to a suction velocity. It is concluded that the location of separation point moves forward as the values of the dimensionless heat transfer parameter $S_{\mathrm{w}}$ increases (heating the wall). On the other hand, application of suction or cooling the wall stabilizes the boundary layer and delays the separation which is very important in Aerodynamics. 


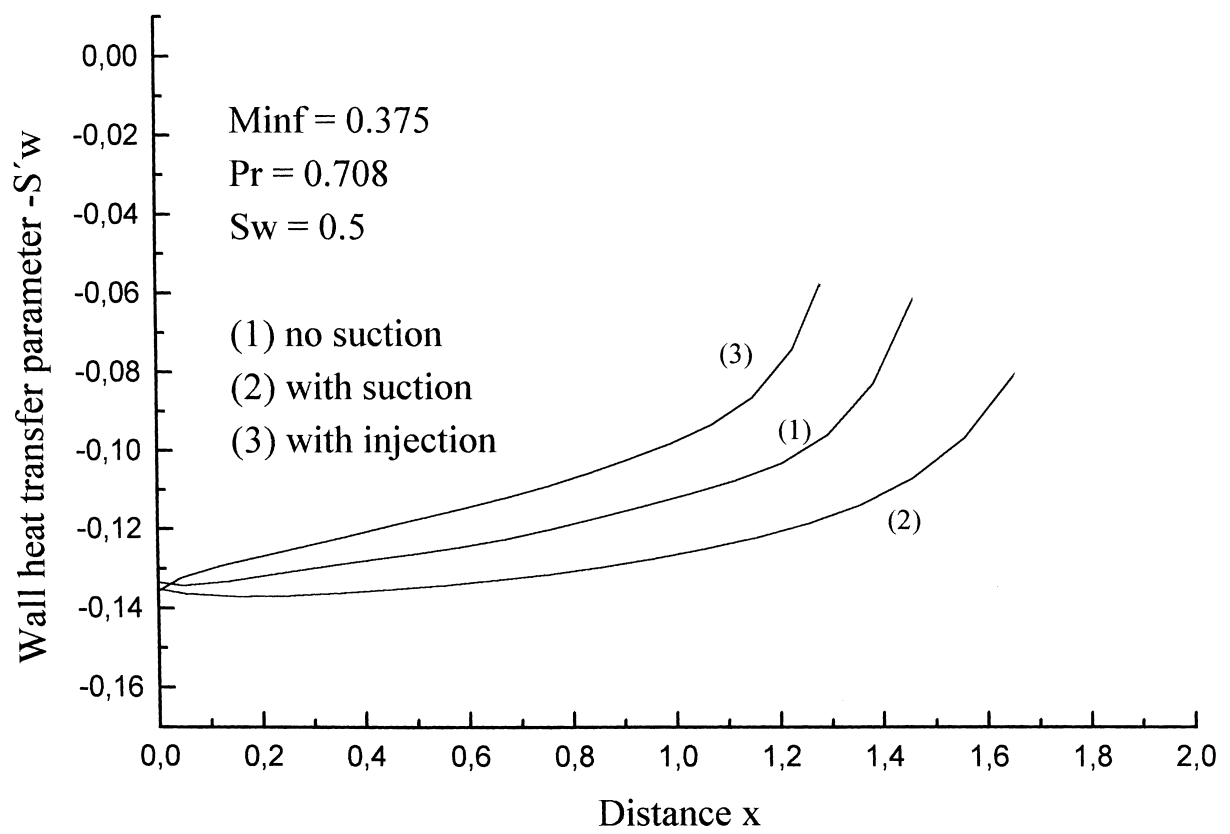

Fig. 14. Variation of the dimensionless wall heat transfer parameter $-S_{\mathrm{w}}^{\prime}$ for $M_{\infty}=0.375$.

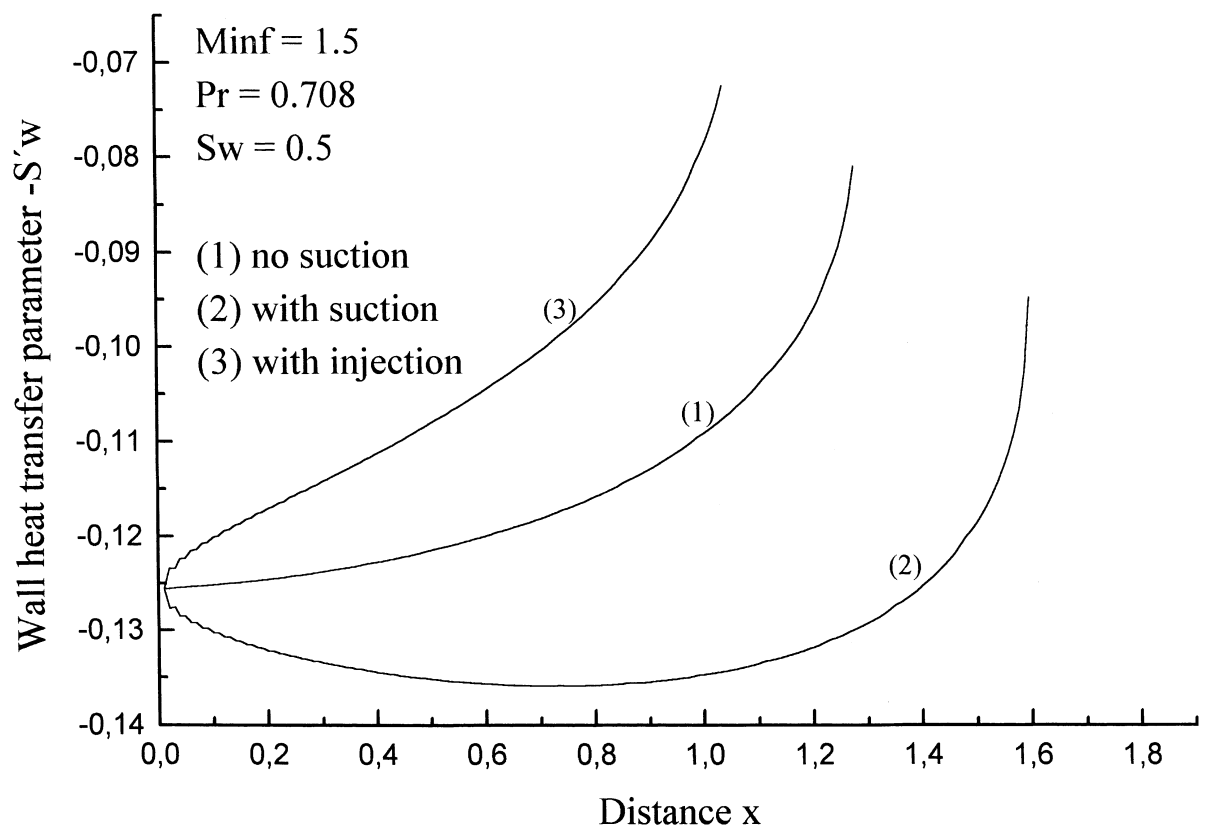

Fig. 15. Variation of the dimensionless wall heat transfer parameter $-S_{\mathrm{w}}^{\prime}$ for $M_{\infty}=1.5$. 


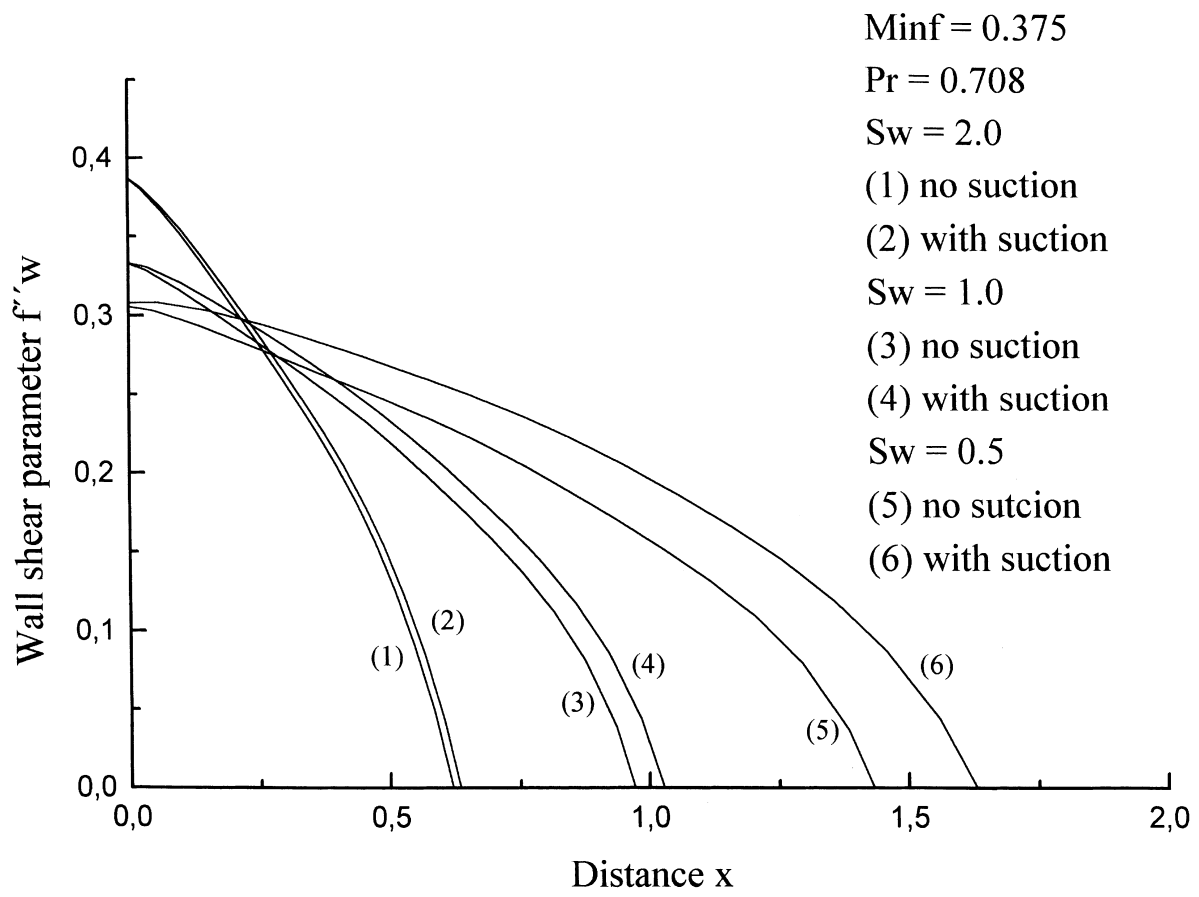

Fig. 16. Variation of the dimensionless wall shear parameter $f_{\mathrm{w}}^{\prime \prime}$ for $M_{\infty}=0.375$.

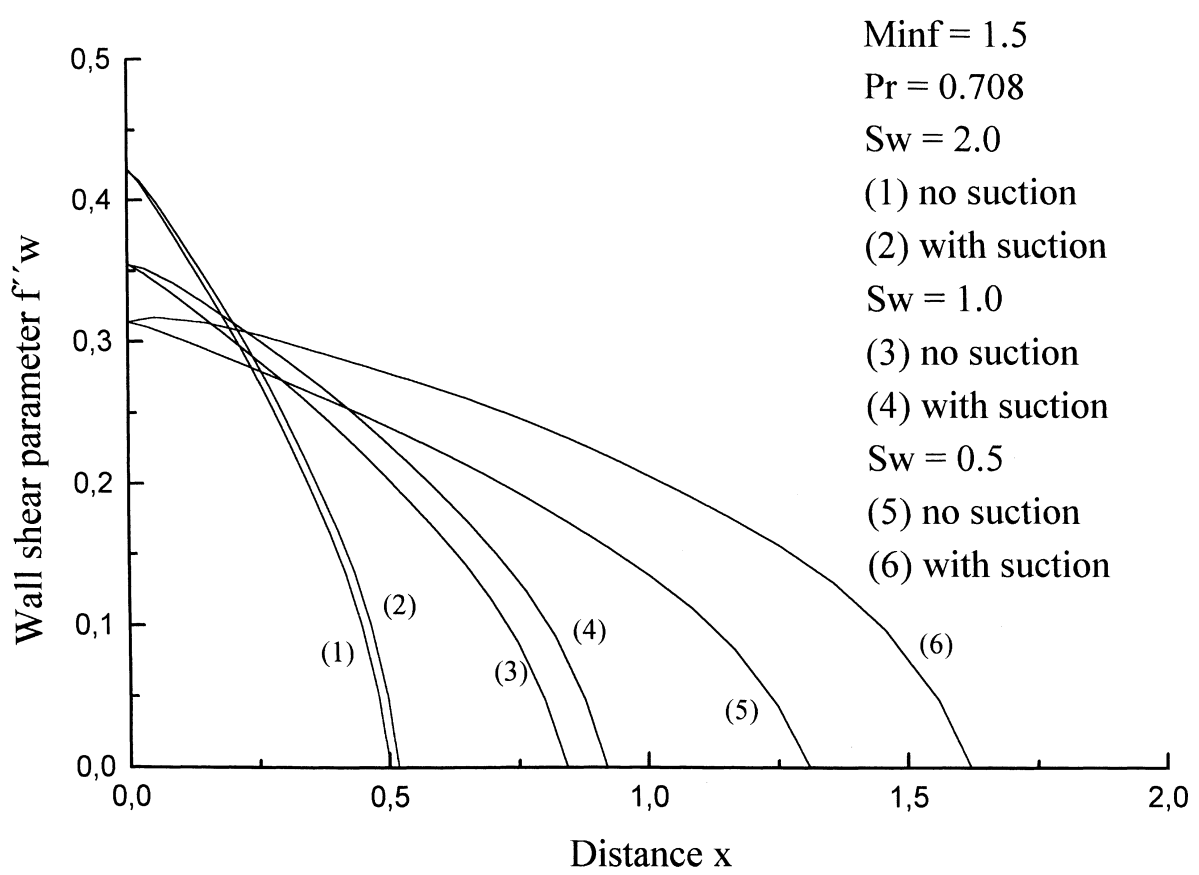

Fig. 17. Variation of the dimensionless wall shear parameter $f_{\mathrm{w}}^{\prime \prime}$ for $M_{\infty}=1.5$. 


\section{Concluding remarks}

The numerical investigation of the steady, two dimensional, compressible, laminar boundary layer with adverse pressure gradient, in the presence of heat and mass transfer, showed that:

1. The flow field is appreciably influenced by the suction/injection velocity imposed at the wall.

2. This influence, on the wall shear parameter and the wall heat transfer parameter, is more evident in the case of suction than that of injection.

3. The separation point is moved towards the leading edge of the wall as the compressibility increases or when the flow is subjected to an injection velocity.

4. Heating the wall moves separation forward the leading edge.

5. Application of suction or cooling the wall stabilizes the boundary layer and delays separation.

\section{Acknowledgements}

This work is partially supported by the AGARD support project G96, Contract No. 457G96B.

\section{References}

[1] P.H. Oosthuizen, W.E. Carscallen, Compressible Fluid Flow, McGraw-Hill, New York, 1997.

[2] G. Kuerti, The laminar boundary layer in compressible flow, Advances in Applied Mechanics 2 (1951) 21-92.

[3] A.D. Young, Section on boundary layers, in: L. Howarth (Ed.), Modern Developments in Fluid Mechanics High Speed Flow, Clarendon Press, Oxford, vol. 1, 1953, pp. 375-475.

[4] N. Curle, The Laminar Boundary Layer Equations, Clarendon Press, Oxford, 1962.

[5] K. Stewartson, The Theory of Laminar Boundary Layers in Compressible Fluids, Oxford, 1964.

[6] A. Walz, Boundary Layer of Flow and Temperature, MIT Press, Cambridge, MA, 1969.

[7] T. Cebeci, A.M.O. Smith, Analysis of Turbulent Boundary Layers, Academic Press, New York, 1974.

[8] S. Schreier, Compressible Flow, Wiley, New York, 1982.

[9] J.D. Anderson, Hypersonic and High-Temperature Gas Dynamics, McGraw-Hill, New York, 1989.

[10] L. Howarth, Proc. Roy. Soc. London A 164 (1938) 547.

[11] H. Schlichting, Boundary-Layer Theory, in: J. Kestin (Ed.), Trans., McGraw-Hill, New York, 1979.

[12] D. Arnal, Control of laminar-turbulent transition for skin-friction drag reduction, in: Control of Flow Instabilities and Unsteady Flows, CISM Course, 18-22 September 1995.

[13] F.M. White, Viscous Fluid Flow, 2nd ed., McGraw-Hill, New York, 1991.

[14] G.E.A. Meier, G.H. Schnerr, Control of Flow Instabilities and Unsteady Flows, CISM Courses and Lectures No. 369, 1996.

[15] T. Cebeci, P. Bradshaw, Physical and Computational Aspects of Convective Heat Transfer, Springer, Berlin, 1984.

[16] H.B. Keller, A new difference scheme for parabolic problems, in: J. Bramble (Ed.), Numerical Solutions of Partial Differential Equations, II, Academic Press, New York, 1970, pp. 265-293.

[17] D.A.S. Rees, Trans. ASME J. Heat Transfer 119 (1997) 792.

[18] D.A.S. Rees, Journal of Porous Media, to appear.

[19] J.X. Ling, A. Dybbs, ASME Paper 87-WA/HT-23, ASME, New York, 1987.

[20] CRC Handbook of Chemistry and Physics, 67th ed., CRS Press, Boca Raton, FL, 1986-1987. 